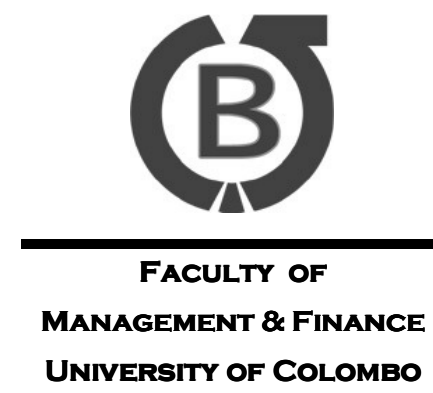

Vol. 07, No. 02, December, 2016
Colombo

Business

Journal

International Journal

of Theory \& Practice

\title{
Ecotourism Practices in Sri Lanka: The Case Study of Rainforest Eco Lodge
}

\author{
S. M. D. Fernando ${ }^{a}$, K. A. S. P. Kaluarachchi ${ }^{b 1}$ \\ ${ }^{a}$ BBA Programme, Department of Management and Organization Studies, University of Colombo, Sri Lanka \\ ${ }^{b}$ Department of Management and Organization Studies, University of Colombo, Sri Lanka
}

\begin{abstract}
Though ecotourism has become a new concept in modern tourism, it has not been practiced by ventures in its true sense. This issue is also true for the eco tourist ventures in Sri Lanka since they have been unable to identify the eco tourist markets and customer segments clearly. As a result, there is a lack of common principles and frameworks of ecotourism to guide the eco tourist ventures who then only try to satisfy their ecotourism destinations to a basic level. Such a short-term orientation can prevent eco tourist ventures to focus more on the sustainability of their business. The present study using a comprehensive framework of ecotourism, examines the ecotourism practices of an ecotourism lodge in Sri Lanka and it has revealed that the company has given attention to the best practices of ecotourism to a greater extent. However, the broader issue faced by the company as an ecotourism venture in Sri Lanka is the lack of ecotourism standards and practices maintained by Sri Lanka as a nation to meet the international ecotourism principles.
\end{abstract}

Keywords: Ecotourism, Ecotourism Practices, International Ecotourism Principles

\section{Introduction}

Ecotourism has emerged as an alternative to mass tourism since the late 1960s triggering a concern for the nature-based elements of holiday activities. In modern tourism there is a high demand for 'ecotourism'; however, it is viewed just another buzzword by some scholars (Sirakaya, Sasidaran, \& Sönmez, 1999). For example, practices such as 'green washing' have undermined its legitimacy, lack of understanding of the term has led to many issues in the practice of ecotourism (Wood, 2002).

There is a lack of common understanding to measure and evaluate the ecotourism practices undertaken by local ventures within an international framework of ecotourism. As a result, many travel and tourism businesses have found that it is convenient to use the term 'ecotourism' and the respective governments have used the term extensively to promote it in their destinations only to a 
basic level (Lindberg, 1991). But the practice of ecotourism needs to be considered and realized focusing on its sustainable use, including the community and ethical aspects, which is more relevant to the ecotourism ventures in the developing context (Australian Department of Tourism, 1994; Beaumont, 1998; Bjork, 2000; Weaver, 1998; Wight, 1993).

However, Honey (2008) has introduced seven principles of ecotourism: (1) involve travel to natural destinations, (2) minimizes impact, (3) builds environmental awareness, (4) provides direct financial benefits for conservation, (5) provides financial benefits and empowerment for local people, (6) respects local culture, and (7) supports human rights and democratic movements; which could generally be used as a common framework to understand the ecotourism practices of the local ventures.

With reference to the local context, many hoteliers in Sri Lanka try to promote the sustainable use of the concept of ecotourism as a new market orientation. But the arrival of eco tourists to Sri Lanka has been less than 1percent in the last decade. This is mainly because, the practice of eco-resort concept has been misused by the hoteliers in Sri Lanka since they are unable to classify the eco tourists and identify the market and customer segments clearly (Arachchi, Yajid, \& Khatibi, 2015).

Moreover, Bandara (2009) has found that although the ecotourism operators in Sri Lanka have identified the importance of having ecotourism policies and procedures in the local context, such policies and procedures have not been implemented according to the international principles of ecotourism, which presents the lack of enthusiasm of them towards the practice of ecotourism in a true sense. Hence, it is argued that ecotourism ventures/operators in Sri Lanka are yet to comply with the international principles of ecotourism in order to satisfy their customers in a more responsive manner.

Although the past studies on ecotourism practices of Sri Lankan ecotourism ventures/operators (Arachchi et al., 2015; Bandara, 2009) are somewhat negative on the market and customer orientation of the ventures/operators, some Sri Lankan ecotourism ventures have been doing their business in a manner that is responsive to stakeholders' views and, as a result, have received prestigious awards for the outstanding service they render to the public. As an example, a Sri Lankan eco tourist lodge namely, the Rainforest Eco Lodge (Pvt) Ltd (Rainforest Eco Lodge - RFEL) which is located in the Sinharaja forest division of Sri Lanka and which is operating as a joint venture for a number of businesses in the ecotourism sector has won popular LEED Platinum Certification and SKAL International Sustainability Awards. The company has been designed and constructed in terms of sustainability and resource conservation principles which significantly comply with the international ecotourism principles. Therefore, the purpose of this study is to examine the ecotourism practices of RFEL, using a guiding framework on international ecotourism principles. The intended purpose of the study was specified further stating the two objectives as to identify the ecotourism practices of RFEL and to analyse major issues faced by RFEL in practicing ecotourism to comply with the international principles of ecotourism.

\section{Review of Literature}

Though there is a limited body of literature still in the field of ecotourism, it was Hetzer who initially introduced the basics of ecotourism in 1965, describing the complex relationship among travellers, environments, and cultures (McLaughlin, 2011; Higham, 2007). He outlined arguably the 
first set of fundamental principles of the concept that shaped the discourse of many definitions later on (McLaughlin, 2011; Higham, 2007).

However it was in the late 1980s that the term ecotourism sparked up as a direct result of the world's acknowledgment towards its practice. For Ceballos-Lascurain (1987), ecotourism refers to travelling to relatively undisturbed or uncontaminated natural areas with the specific objective of studying, admiring, and enjoying the scenery and its wild plants and animals, as well as any existing cultural manifestations. Ziffer (1989, p.6) defined ecotourism as "a form of tourism inspired primarily by the natural history of an area, including its indigenous cultures". The eco-tourist visits relatively undeveloped areas in the spirit of appreciation, participation, and sensitivity with a non-consumptive use of wildlife and natural resources and contributes to the visited area through labour or financial means aimed at directly benefiting the conservation of the site and the economic well-being of the local residents. However, for Bjork (2000), ecotourism must be sustainable and it is cooperated with four central groups of actors namely; local people, the authorities, tourists and companies involved in tourism.

Many research findings on ecotourism in less developed countries indicate that domestic participation is limited and the community which is directly affected is also negligible (Weaver, 1998). Hence sustainable ecotourism imposes an 'ethical overlay' on nature-based tourism as mentioned in Wight (1993). According to Beaumont's (1998) approach to ecotourism, it is a subset of nature tourism, which in turn is a subset of tourism. It is further defined by Australian Department of Tourism (1994) as nature-based tourism that involves education and interpretation of natural environment which is environmentally sustainable.

Highlighting the need of having a common framework to understand the concept and its practice, Boo (1990) suggested that, for ecotourism to reveal its benefits effective planning and strategies are required, so that conservation of resources could address the sustainable management of such resources. However, the author specifies that the benefits of ecotourism given to the destination largely depend on the scale of tourism, the country size, and the interconnected parts of the economy. In order to balance the need of having a common understanding and to enhance the possible benefits to the destination which tries to adopt the concept of ecotourism, Honey (2008) has suggested seven principles of ecotourism which are outlined as follows.

1. Travel to natural destinations: This stresses the importance of ensuring that ecotourism operates in a natural environment and not in an artificially created and pretending environment. Hence, minimum levels of artificial material and artefacts should be used in construction and operations.

2. Minimizes impact: This principle invites minimizing the impact of development and tourist activity by choosing appropriate building materials, renewable energy sources, visitor management strategies, monitoring techniques, and conservation plans.

3. Builds environmental awareness: This includes educational and interpretational material for visitors, educational training for guides, and educating the greater public and surrounding community.

4. Provides direct financial benefit for conservation: Direct financial contributions should be made out of the revenue towards conserving the surrounding environment and ensure its sustenance.

5. Provides financial benefits and empowerment for local people: The principle covers employment of local people, using an all-inclusive stakeholder approach to planning, management, and policy development and fostering of partnerships. 
6. Respects local culture: Activities conflicting with the local culture should be avoided to ensure minimal disruption.

7. Supports human rights and democratic movements: This is mostly related to ecotourism ventures in developing nations. It attempts to draw attention to political systems of the host countries and their people to foster an international understanding of peace, prosperity, and universal respect or and observance of human rights and fundamental freedoms for all.

These seven principles of ecotourism which have been applied by Honey (2008) to study the ecotourism practices in developing contexts (in Africa and South America) were used as the theoretical lens for examining ecotourism practice of the Sri Lankan case in this study.

\section{Methods}

The case method (Yin, 2003) was used as the approach of the study by selecting RFEL where the empirical study was carried out.

\subsection{Data Gathering}

As the first step of gathering data, permission was obtained from the RFEL. A data gathering guidelines along with an interview guide was developed encompassing the requirements, measurements and type of data (Yin, 2003). The requirements of data were categorized focusing the seven principles of ecotourism (Honey, 2008). The carefully conducted case study benefited from having multiple sources of evidence: documents, archival records, interviews, direct observations, participant-observations, and physical artefacts. Based on the scope of the research, unstructured interviews were held ranging from ten to forty five minutes. The interviews were carried out in both English and Sinhala languages where the answers given by the informants were translated in to English when they were used for the analysis. Some of the interviews were audio recorded while taking complimenting notes depending on the circumstances and the suitability. Different protocols were designed for the interviews with different types of participants in the study. A wide range of participants were used to obtain a holistic view on the case. In particular, nine participants were interviewed to reflect the various levels of the hierarchy which consist of the Chief Executive Officer (CEO), Manager-Operations, an interpreter (Guide), two operational level employees, two guests of the lodge and two participants from the local community.

\subsection{Data Analysis}

The study mainly used the thematic analysis as the method of analysing data qualitatively (Yin, 2003). This substantially helped to accomplish the two research objectives in line with the categorized themes considered, pertaining to the seven principles of ecotourism with respect to the case. The analysis also facilitated to converge the sources and results of data to be triangulated in the forms of data provided from different sources (Yin, 2003).

\section{The Case and Findings}

Being a developing country, Sri Lanka has a great potential for ecotourism. It encompasses a wide variety of scenic and ecologically important natural habitats and possesses some of the richest floral and faunal biodiversity in the region.

The case under study, RFEL, is situated in the Sinharaja Division of the Enesalwatte Estate in Viharahena, Deniyaya. This plot of previously cultivated tea land, borders the South - Eastern fringe 
of the Sinharaja Forest Reserve, a UNESCO Natural World Heritage Site inscribed in 1988. The Sinharaja is also a UNESCO Biosphere Reserve, and a bio diversity hotspot as designated by the International Union for Conservation of Nature (IUCN). All these titles highlight the importance of the forest reserve, and hence the location of the lodge, in terms of its bio diversity as well as the fragility. As such, in selecting this location, the management of the eco-lodge has recognized the importance of committing to the conservation of its surroundings and promoting the cause through its development and operations. The vegetation that predominate the Sinharaja Forest Reserve belongs to the tropical (lower-montane) wet evergreen forest type. This is a unique type of the forest which is very low in abundance in a global context, and is the only piece of pristine forest that Sri Lanka can claim ownership to. Most of the plant species in this forest are considered to be rare and over 60 percent of these species are endemic. This unique vegetation type therefore also plays host to a unique collection of faunal species which consist of over 90 percent of Sri Lanka's endemic birds and over 50 percent of endemic butterflies, mammals, insects, reptiles, and amphibians. This unique degree of bio diversity provides RFEL with the perfect natural setting, which is an essential component of international principles of ecotourism.

The Lodge consists of sixteen comfortable chalets. Each chalet consists of a bedroom, a washroom, a living room, and a private observation deck. Conforming to a world renowned ecotourism concept, each chalet is architecturally designed using two and a half recycled shipping containers and is perched on stilts above the tea patch. The interior is ideally decorated with recycled bamboo panelling while the floor and private deck resemble recycled railway sleepers. The chalets are situated among a tea patch and offer guests breath-taking views of the forest canopy and tea estate. Guests can experience the waves of mist that appear in a split second and last just as long. It has been designed and constructed according to the most stringent standards in terms of sustainability and resource conservation and it has won the prestigious awards of LEED Platinum Certification and SKAL International Sustainability Award.

RFEL at its inception had been consulted by Meghan Epler Wood, a renowned academic of the domain of ecotourism and the founder of the International Ecotourism Society. As a result, the management of the Lodge has done a thorough analysis on the subject and decided to revolve the initiatives as best practices of ecotourism in the forms of (1) Designing and managing environmental best practices following the international guidelines on ecotourism, (2) Community outreach programmes in a process of sustainable development to integrate the residence community in the area it lives in, (3) To support conservation activities in the forest which has also been named in the World Heritage Site of UNESCO, (4) An awareness campaign through the strategic alliances with academics professionals, cultural institutions, conservationists, media, and the international eco-cultural market to boost the country's potentiality in ecotourism, and (5) Independent evaluation of environmental and socio-economic sustainability with the intention of formulating the international standards for ecotourism in Sri Lanka.

The ecotourism practices of RFEL are presented below in relation to the seven principles of ecotourism introduced by Honey (2008). 


\subsection{Findings in Relation to the Framework of Honey (2008)}

Involves Travel to Natural Destinations

This principle highlights the fact that ecotourism can be carried out only in a natural setting and not in an artificially created environment. This has been assessed using some of the criteria presented below.

Design and Construction Materials Used: The chalets have been mainly made out of recycled shipping containers. This creates a point for argument and goes against the norm of pure natural materials being used.

People think that an eco-lodge should be made out of clay, wood, woven coconut palms, mana (grass) and all that. But we have made our Lodge by recycled shipping containers, glasses, and steel. It is because of that the main idea of building an eco-lodge should be to make the least impact on the environment. There is no point of cutting trees and other activities which can harm the natural environment. The things that we have used have already had its past life and that way we have minimized the use of new resources specifically for our purpose. (Participant 1)

It was observed that most of the materials recycled have been used to construct the lodge. In doing this, it has been concerned on the concept of 3Rs: Recycle, Reduce, and Re-use.

Guest Exposure to Nature: The Lodge is located in the border of the Sinharaja Rainforest, and thus it provides the guests an authentic rainforest experience. The chalets are located in the open area with insect movements where the guests are directly exposed to the nature. An organic garden is been maintained to source vegetables and fruits in their natural form.

\section{Minimizes Impact}

Area Cleared for Construction: A very small area has been cleared in patches for the purpose of construction, which has not affected badly to the activities of tourists. This seems an effective visitor management strategy used by the Lodge.

Landscaping and Visual Impact: The views of the forest and the tea estates provide the amazing image of different shades of green. On-site observations also confirmed the same. A participant in the study claimed that:

Artificial landscaping has been minimized to protect the visual impact of the lush greenery. Only the essential pathways to the chalets have been paved with stones. (Participant 2)

Energy Consumption Reduction Measures: The Lodge has taken number of measures to reduce its energy consumption. For example, air conditioners and televisions have not been fixed and the fans are only available on request if they are essential for comfort of the guests. Further, the guests are advised to switch-off the extra lights and power devices, especially when they leave the rooms. In response to the regulations of the Central Environment Authority, it has outsourced the laundry service. Guests are required to re-use the towels and linen by taking a small step towards helping the rainforests to last another lifetime and be preserved for the next generation.

Waste Management Processes: According to the study participants as well as the observations, clear effort and considerations are being given to manage the waste. It was claimed that: 
The kitchen food waste is being utilized by a biogas plant and the kitchen waste water is being purified using a water treatment plant which costs more than rupees two million. The garbage is separated. The empty cans are transferred to a villager producing garden broomsticks and the empty bottles are given to villagers who produce Kithul honey and toddy. This minimizes the quantity of wastage to be cleared by the local authorities. (Participant 3)

In addition, smoking has been prohibited within premises in order to prevent potential fire hazards when disposing smoked cigarettes.

Noise Generation and Disruption to Natural Habitats: In the phase studying feasibility of the project, some environmental specialists and academics were consulted to study the natural habitats in the surrounding areas to identify the potential threats or disturbances to the operations of the Lodge. It maintains a very low level of noise, so that the guests can enjoy the nature with minimum disturbance.

\section{Builds Environmental Awareness}

This deals with the educational aspect of ecotourism which is an essential element. This has many dimensions out of which a few have been discussed.

Availability of Pre-Tour Educational Materials: The availability of pre-tour educational materials was explained as:

This process starts from the company website (www.rainforest-ecolodge.com) where potential guests browse for information. It includes very detailed explanations about the Sinharaja Rainforest, its bio diversity of fauna and flora and what is to be experienced at the Eco Lodge. (Participant 4)

It was also noted that a detailed booklet is kept in each room for the reference of the guests. A short briefing is done before every nature trek, explaining what attractions are possible to be seen, and precautionary measures that requires to be followed.

Accessibility to Interpretation and Guiding: According to the Interpreter interviewed:

Four nature interpreters are employed under the Rain Forest Eco lodge. We are from the areas nearby and already have had a basic knowledge about the rainforest which we gathered since childhood. The company also enrols us for training at open-university courses in particular on wildlife conservation. (Participant 5)

A comprehensive training manual for nature interpreters has been prepared by the Lodge, not only for the interpreters but also for the benefit of other staff members and the guests. The interpreters also gather knowledge by reading publications of popular authors on wildlife and always they are eager to be updated.

The company very recently opened a well detailed Interpretation Centre, becoming Sri Lanka's first nature-based hotel to do so. It has been established as a knowledge hub designed to emulate the rainforest ecosystem, as a preliminary step in exposing visitors to the real conditions of the rainforest. It provides visitors with an opportunity to understand the basic components of the complex environment they will soon venture in to.

Staff and Community Awareness: A consultant trainer is brought into the Lodge biannually to enhance the awareness of staff and community. Most staff members have an interest in sharing 
information about the climate, rainforest, and its characteristics at a commendable level. The awareness among the local communities has also been created at the school level where their children have been thought about the negative effects of deforestation.

\section{Provides Direct Financial Benefits for Conservation}

Donations for Conservation Projects and Its Percentage of Revenue/Profit: The sixth participant in the inquiry on this point stated that:

We are still studying the surroundings in order to identify the requirements for major conservation projects. Apart from the little initiatives we made on this, a large-scale project needs to be carried out in future. (Participant 6)

However, the management reserves an annual contribution of 1 percent of turnover to fund the projects on community development and environmental conservation.

\section{Provides Financial Benefits and Empowerment for Local People}

The involvement and interaction with the local communities and empowering them is a vital component of ecotourism which also has a range of perspectives.

Donations to Community Development Projects: To uplift the standard of living, the Lodge has begun some community development projects with USAID in 2005. These projects are still going on as a part of this movement. Under this programme, 35 brand new residential units were constructed for members of the community who were requested to relocate and be away from the construction of the Lodge. In addition, a primary school and a healthcare center have also been constructed for the local community.

Community Development Projects: After doing a research to understand the needs of the community, health clinics and various other workshops were conducted and such programmes are still being carried out upon the requests of the community. The Lodge also plays a pivotal role to ensure the access of community to energy, potable water resources, public transportation, and the other infrastructural facilities. All these activities were confirmed to be true according to the members of the local community who were interviewed during the study.

However, the two members who were interviewed said that the involvement of the local community in the process of planning and decision making could have been increased further.

Percentage of Employees from the Local Area: Around 85 percent of employees are from the nearby area within a radius of $15 \mathrm{~km}$. Hence they are treated in a respectable manner. For example, the company has funded an employee to be trained at the Ceylon Hotel School, who will be graduating in the next year. However, the management feels that it is still early for employees to be allocated to the key managerial positions. This is an issue to be addressed in future.

Promotion of Locally Produced Products and Services: The goods are procured from the local suppliers. This mechanism has also provided avenues for the promotion of local agriculture and organic cultivation within the community. 


\section{Respects Local Culture}

This involves the avoidance of activities which might be in conflict with the local culture. The issue is mostly being handled by the travel agents through whom the guests arrive. Guests are also provided with opportunities to taste predominantly local cuisine while western cuisine is also served to add variety. The meals offered to the guests have a good variety of local dishes, which is also an insight to preserve the local culture.

\section{Supports Human Rights and Democratic Movements}

This is a principle which has been given attention, especially in developing countries. It is discussed under several criteria.

Avoidance of Discrimination: The racial composition of the employees has an almost equal split between Sinhalese and Tamils. Therefore, the management is confident about the fact that there is no such discrimination prevalent in the organization.

Adherence to Labour Laws and Salary Structures: The employees are satisfied with their working conditions and they believe that their salaries are well within the average salary limit of the industry. The employees are also provided with accommodation, meals, basic salary, and service charges as provided by other hotels.

Although the Lodge has adhered to the seven principles of ecotourism introduced by Honey (2008), it does face some issue in practicing ecotourism.

\subsection{Issues in complying with International Principles of Ecotourism}

The interviews with different kinds of study participants and other sources of data highlighted various issues that are being faced by the ventures in trying to comply with the international principles of ecotourism. The major issue highlighted by the participants is that the clientele of ecotourism is not being attracted to the country on genuine grounds. Many respondents shared the view that presently Sri Lanka is not a popular destination to ecotourism compared to the eco-tourist countries like Costa Rica and Brazil. Hence there is a significant lack of genuine effort made to attract eco-tourists to Sri Lanka. Despite the high bio-diversity it has, Sri Lanka is still not being branded and promoted much as a destination to ecotourism. A participant of the study elaborated this major issue in the following manner.

\footnotetext{
Although eco-tourists can be categorized as hard and soft, the clientele of them in Sri Lanka hardly belonging to these. Hence the tourists coming to the country are looking for short nature experience as a little part of their whole tour. This issue at time has led to a serious mismatch between the clientele of ecotourism and the service offering by focusing on the international principles of ecotourism. (Participant 7)
}

The current clientele of ecotourism is tried to be satisfied with the luxuries but without understanding the concept of green luxury that is being offered by the ventures of ecotourism in other countries. As a result, eco-tourists prefer to have direct exposure to nature and culture just as a minor part of a long tour.

About 90 percent of the guests exhibit a substantial fear of the leeches and the other species when trekking through the forest. This would not be the case usually should be when we promote ecotourism. (Participant 8) 
The current clientele usually spends only one or two nights at the Lodge since it is just a part of a round tour. Pure eco-tourists are always focused on making the least impact. However, the clientele here is looking at the maximum level of facilities provided, despite the impact on the environment. These issues are unlikely to appear when catering to pure eco tourists who would understand the scope and regulations under which an eco-lodge situated within a strict natural reserve has to operate. Hence genuine eco-tourists are usually willing to pay a premium price for an authentic service offering in ecotourism. However, the current clientele has often complained that the price charged from them is too high. One of the main reasons behind this is that an eco-tourist pays for the experience, while a normal tourist pays for the facilities received.

These issues were further evidenced by the two casual interviews conducted with two guests at the Lodge. They had a total stay in Sri Lanka of 11 and 9 nights each, while the stay at the eco lodge was 2 nights and 1 night respectively. Both of them didn't identify themselves as eco tourists but ordinary tourists with an interest in experiencing nature. One of them was very satisfied with the experience while the other thought that the price charged was too high for the facilities provided and had many grievances regarding the overall service.

Apart from having lack of genuine eco-tourists, one of the major issues that RFEL had was the challenges it faced during start-up of its business. The company had to go through lot of red tape before it was finally being able to convince the authorities about the true nature and benefits of ecotourism.

\section{Discussion}

In both developed and developing contexts, the new management concepts like 'ecotourism' are tried to understand and practice as 'buzz words' where finding a common understanding to have expected results from the practice is less seen (Sirakaya et al., 1999; Wood, 2002; Lindberg, 1991; Boo, 1990). The issue is common to the eco tourist ventures/operators in Sri Lanka since they have been struggling to promote the sustainable use of ecotourism as a new market orientation (Bjork, 2000; Weaver, 1998; Wight, 1993; Beaumont, 1998; Australian Department of Tourism, 1994; Arachchi et al., 2015; Bandara, 2009).

Honey (2008) has introduced seven principles of ecotourism which could be used as a comprehensive framework to understand the ecotourism practices of firms. Using Honey's (2008) framework on ecotourism, the present study examined the ecotourism practices of RFEL. It was noted that the company at its inception had initiated some best practices of ecotourism in the forms of designing and managing environmental best practices, community outreach programmes, supporting conservation activities in the forest, etc. which comply with the basic requirements of ecotourism suggested in Ceballos-Lascurain (1987) and Ziffer (1989). The in depth qualitative data analysis based on the thematic narratives obtained from the participants of the study revealed that the Lodge deals significantly with the practices of travelling to natural destinations, attempting to minimize the impact, building environmental awareness, providing direct financial benefits for conservation, providing financial benefits and empowerment for local people, respecting local culture, and supporting human rights and democratic movements as major ecotourism practices of the company (Honey, 2008). 
Using the framework of international ecotourism principles (Honey, 2008) as the theoretical lens, the present study examined the ecotourism practices of RFEL. It was revealed that the company at its initial formation had given attention to the best practices of ecotourism to a greater extent. However, as guided by the Honey's (2008) framework, major ecotourism practices and the respective measures of the Lodge are summarized in Table 1.

\section{Table 1: RFEL Practices in Accordance with Horney (2008) Framework}

\begin{tabular}{|c|c|c|}
\hline & Dimension & Practices \\
\hline 1. & Involve travel to natural destinations & $\begin{array}{l}\text { Design and construction materials used } \\
\text { Guest exposure to nature }\end{array}$ \\
\hline 2. & Minimize impact & $\begin{array}{l}\text { Area cleared for construction } \\
\text { Landscaping and visual impact } \\
\text { Energy consumption reduction measures } \\
\text { Waste management processes } \\
\text { Noise generation and disruption to natural habitats }\end{array}$ \\
\hline 3. & Build environmental awareness & $\begin{array}{l}\text { Availability of pre-tour educational materials } \\
\text { Accessibility to interpretation and guiding } \\
\text { Staff and community awareness }\end{array}$ \\
\hline 4. & $\begin{array}{l}\text { Provide direct financial benefits for } \\
\text { conservation }\end{array}$ & $\begin{array}{l}\text { Donations for conservation projects and its percentage } \\
\text { of revenue/profit }\end{array}$ \\
\hline 5. & $\begin{array}{l}\text { Provide financial benefits and } \\
\text { empowerment for local people }\end{array}$ & $\begin{array}{l}\text { Donations to community development projects } \\
\text { Community development projects } \\
\text { Percentage of employees from the local area } \\
\text { Promotion of locally produced products and services }\end{array}$ \\
\hline 6. & Respect for local culture & $\begin{array}{l}\text { The issue is mostly being handled by the travel agents } \\
\text { through whom the guests arrive. Guests are also } \\
\text { provided with opportunities to taste predominantly } \\
\text { local cuisine while western cuisine is also served to } \\
\text { add variety. }\end{array}$ \\
\hline 7. & $\begin{array}{l}\text { Support human rights and democratic } \\
\text { movements }\end{array}$ & $\begin{array}{l}\text { Avoidance of discrimination } \\
\text { Adherence to labour laws and salary structures }\end{array}$ \\
\hline
\end{tabular}

Hence, the findings on ecotourism practices of RFEL illustrate its focus on promoting the sustainable use of ecotourism (e.g., Bjork, 2000), which seems to challenge the literature on ecotourism in Sri Lanka found in Arachchi et al. (2015) and Bandara (2009). Instead, the issue seems to be that the current tourist clientele of Sri Lanka are not tourist who can be categorized as ecotourists.

\section{Conclusion}

Major issues faced by the Lodge in compliance to the international ecotourism principles were identified with the lack of eco-tourists who are genuinely attracted to Sri Lanka. This has created a mismatch between the service offering and the expectations of the clientele. The current clientele of the Lodge mainly consists of the normal tourists with a slight interest of having an experience with nature as a part of their longer tour. Hence the length of stays by the guests seems to be low, while 
they are not prepared to pay a premium price due to the lack of facilities and services provided by the hotels.

Apart from having lack of genuine eco-tourists, one of the major issues that RFEL had was the challenges it faced during start-up of its business. The company had to go through lot of red tape before it was finally able to convince the authorities about the true nature and benefits of the ecotourism providing a natural setting by not harming the environment. It had also given attention to minimize the negative impact on environment by introducing effective energy consumption measures, noise reduction measures, and placing proactive waste management processes in its many aspects of operations. A greater commitment had been made towards building the environmental awareness by making the availability of its pre-tour educational materials, providing well knowledgeable and trained interpreters on nature, and building awareness of nature among its staff and the local community. Even though the company is still being evaluated to fund an environmental conservation project in a significant size, the annual contribution made from its turnover seems to be trustworthy to undertake the task in the near future.

A significant portion of the local community has been empowered through many aspects of housing, education, healthcare, and infrastructure. Local residents consist of around 85 percent of the workforce and are being provided with ample training opportunities. Locally produced products are also promoted as much as possible. However, when considering the information provision with regard to the local culture, it was identified that due to very short stays at the eco-lodge, there was not sufficient time for guests to be exposed to the local culture. Information provision is often done by the travel agents and not the Lodge. The key experience of local culture lies in being able to taste the local dishes prepared using organic ingredients and gourmet skills. The Lodge has displayed no hindrance to supporting the human rights and the employees have been satisfied mainly with no discrimination in the premises.

\subsection{Implications}

The findings of the present study could be helpful to managers of local firms and organizations which directly and indirectly engage in the businesses of ecotourism to do such businesses by understanding the importance of adhering to the international principles of ecotourism (Honey, 2008). Moreover, the findings could also be helpful to all institutions and bodies in Sri Lanka which lead to make policies on ecotourism in the country in compliance with the international principles of ecotourism, which in turn could allow to attract more eco-tourists to the country in long-term. The prevailing limitations of this study arise due to the use of a single case to examine the issue. Similar studies in future need to replicate the present study by choosing more cases, survey research, or any other longitudinal approaches to understand the issue of ecotourism practices in Sri Lanka with new knowledge.

Although Sri Lanka has experienced a boom in tourism in her post-war period, due attention has not yet been given to the potential of ecotourism although the country is a hot spot with its high biodiversity. Moreover, ecotourism has the potential to propel the tourism industry of the country into a new destination. The development of the ecotourism industry can bring in many economic benefits as well as means of environmental conservation to the country. In this effort, all ecotourism ventures of the country and the prevailing government should jointly work to formulate both policies and guidelines for enhancing the standard and quality of the service. This will authenticate the practice of 
ecotourism by all local ventures towards a global framework of ecotourism. Further to this, such ventures need to be encouraged by providing more concessions to comply with the international standards in ecotourism. Within these issues and challenges seen at the national level, the RFEL case study is likely to be a local model to understand the timely need of practicing ecotourism in Sri Lanka within the international principles of ecotourism.

\section{References}

Arachchi, R. S. S. W., Yajid, M. S. A., \& Khatibi, A. (2015). Ecotourism practices in Sri Lankan eco resorts: A supplier perspective analysis. Journal of Tourism and Hospitality Management, 3(9), 169-180.

Australian Department of Tourism (1994). National ecotourism strategy. Canberra: Australian Government Publishing Service.

Bandara, R. (2009). The practice of ecotourism in Sri Lanka: An assessment of operator compliance towards international ecotourism guidelines. South Asia Economic Journal, 10(2), 471-492.

Beaument, N. (1998). The meaning of ecotourism according to... Is there new consensus for defining this natural phenomenon? An Australian perspective. Pacific Tourism Review, 2(3/4), 239-250.

Bjork, P. (2000). Ecotourism from a conceptual perspective: An extended definition of a unique tourism form. International Journal of Tourism Research, 2, 189-202.

Boo, E. (1990). Ecotourism: The potential and pitfalls. Washington, DC: World Wide Fund for Nature.

Ceballos-Lascurain, H. (1987). The future of ecotourism. Mexico Journal (January), 13-14.

Higham, J. (2007). Ecotourism: Competing and conflicting schools of thought. In J. Higham (Ed.), Critical issues in ecotourism: Understanding a complex tourism phenomenon (pp. 1-19). Oxford: Elsevier.

Honey, M. (2008). Ecotourism and sustainable development: Who owns paradise? ( ${ }^{\text {nd }}$ ed.). Washington, DC: Island Press.

Lindberg, K. (1991). Policies for maximizing nature: Tourism's ecological and economic benefits. Washington, D.C: World Resources Institute.

McLaughlin, J. M. (2011). Ecotourism assessment: Applying the principles of ecotourism to paddlebased recreation in St. Lawrence Islands National Park and Environs. Ontario: Queen's University.

Sirakaya, E., Sasidharan, V., \& Sönmez, S. (1999). Redefining ecotourism: The need for a supply-side view. Journal of Travel Research, 38(2), 168-172.

Weaver, D. B. (1998). Ecotourism in the less developed world. Wallingford, Oxen: CAB International.

Wood, E.M. (2002). Ecotourism: Principals, practices, policies for sustainability ( $1^{\text {st }}$ ed.). Paris: United Nations Publications.

Wight, P. A. (1993). Sustainable tourism: Balancing economic, environmental and social goals within an ethical framework. Journal of Tourism Studies, 4, 54-56.

Yin, R. K. (2003). Case study research: Design and methods ( $3^{\text {rd }}$ ed.). Thousand Oaks, CA: Sage.

Ziffer, K.A. (1989). Ecotourism: The uneasy alliance. Washington, DC: Conservation International and Ernst \& Young. 